\title{
A NEW SALMONELLA TYPE: SALMONELLA NAGOYA
}

\section{KoJI NAKAJIMA AND SHONOSUKE NAITO}

Joto Hospital, Nagoya

\section{RINTARO NAKAYA AND HIDEO FUKUMI}

The National Institute of Health

(Enterobacteriaceae Center of Japan)

Toky.o, Japan

(Received: October 11th, 1952)

The present paper is dealing with a new Salmonella type isolated from three cases of acute gastroenteritis occurred in a family. The organism has typical cultural and biochemical characteristics of the members of Salmonella group and is considered to be a new type belonging to $\mathrm{C}_{2}$ group.

\section{Case Report}

A 44 years old female and a 20 years old male were admitted to the Joto Hospital, Nagoya, on September 28, 1951, complaining of general malaise, high fever, anorexia, abdominal pain and diarrhea.

Pus, mucus and blood were observed in the stool of the male patient, and yellow mucus in the watery stool of the femal patient.

Their general condition appeared serious.

A type of Salmonella strain was isolated from the stool. As both patients were from the same family, we examined the remaining members of the family, and isolated from a 7 year old girl a Salmonella strain on October 2nd.

The fever was $38.0^{\circ} \mathrm{C}$ to $39.5^{\circ} \mathrm{C}$ at onset of the disease.

Laboratory findings of the first 2 cases:

Blood: hemoglobin $(12.4-11.7 \mathrm{~g} / \mathrm{dl})$ and erythrocyte $\left(4.47-3.43 \mathrm{million} / \mathrm{mm}^{3}\right)$, were within normal limits. Leucocyte counts were $4380 / \mathrm{mm}^{3}$ in one case and $9300 / \mathrm{mm}^{3}$ in the other. Eosinophiles were not seen, immature neutrophiles $(15.0-37.5 \%)$ and monocytes (14.5-15.5\%) were increased. Lymphocytes decreased $13.0-26.5 \%$ and plasma cells were seen $(0.5-1.0 \%)$.

Salmonella was negative by blood cultures in bile medium.

Urine: Both were diazo-reaction positive and one showed protein positive with sulfosalicylic acid. Salmonella was negative in Kauffmann's medium.

Feces: Salmonella was positive on S. S. agar and B. T. B. Drigalski's medium.

Clinical course of the disease:

Remittant fever continued for 3 to 4 days, then gradually declined.

At the beginning, there were frequent discharges of stool ( 7 to 10 times daily), but after the 7 th day one motion daily. 
It required 7 to 9 days for the feces to become normal in appearance.

This Salmonella isolation from the cultures of the feces was positive until the 24th day of illness in all the patients.

As to the source and spreading of infection, it was not determined.

Isolation of the same Salmonella organism from all three patients and the clinical findings mentioned above, indicate that the organism should be the causative agent of these acute gastroenteritis.

\section{BeHAVIOR OF THE ISOLATED ORGANISM}

Three strains isolated from three patients were numbered 1785, 1786 and 1787 respectively. They were all the same in biological and serological characteristics.

\section{Cultural and biochemical behavior:}

Gram negative, motile rod-shaped organism. No fermentation of lactose, sucrose, salicin, adonitol and inositol. Production of acid and gas from glucose. Production of acid from mannitol, dulcitol, sorbitol, maltose, arabinose, rhamnose, xylose, and trehalose. No production of indole. Methyl-red positive but Voges-Proskauer negative. Growth on Simmons' citrate-medium. Production of $\mathrm{H}_{2} \mathrm{~S}$. No coagulation of milk and no liquefaction of gelatin. No decomposition of urea. Positive in Stern's glycerol fuchsin broth. Rhamnose, glucose and arabinose are decomposed but ducitol is not in Bitter's medium. Growth in Simmons' rhamnose, glucose, arabinose and dulcitol.

\section{Serological behaviour:}

The organism in question was agglutinated by $O$ serum of $C_{2}$ group (VI, VIII), and of $\mathrm{C}_{1}$ group (VI, VII), and furthermore, by the $\mathrm{O}$ factor serum containing only VIII, but not by the serum containing only VII. The $\mathrm{O}$ serum against Salmonella glostrup (VI, VIII) was entirely absorbed by the organism in question and vice versa. The result of these tests indicates that the 0 antigen pattern of this organism is VI, VIII.

The organism in question was agglutinated by the $\mathrm{H}$ serum (b) of Salmonella paratyphi $B$ var. java (IV, V, XII:b:-) and by the $\mathrm{H}$ serum $(1,5)$ of S. thompson var. berlin 2988 (VI, VII:-:1, 5), and furthermore, by the second phase $H$ serum $(1,2,3)$ or $(1,2)$ of Salmonella newport var. puerto-rico (VI, VIII:-:1, 2, 3) or Salmonella paratyphi $B 8006$ (IV, V, XII:b:1, 2). It was agglutinated further by the $\mathrm{H}$ factor serum (3), or (5), but not in the $\mathrm{H}$ factor serum(2), (6) or (7). This organism removed all the agglutinins from the $\mathrm{H}$ factor serum (b) and the $\mathrm{H}$ serum $(1,5)$. This experimental result suggests $b$ for the first phase, and 1,5 for the second phase of this organism.

The first phase $\mathrm{H}$ serum of the organism agglutinated $S$. paratyphi $B$ var. java and the second phase $\mathrm{H}$ serum agglutinated the second phase cultures of S. thompson var, berlin 2988, S. newport var. puerto-rico, S. paratyphi $B 8006$. 
S. paratyphi $B$ var. java removed all the agglutinins of the first phase $\mathbf{H}$ serum of this type of organism. All the $\mathrm{H}$ agglutinins were removed from the second phase $\mathrm{H}$ serum of the organism by absorption with both $S$. thompson var. berlin 2988 and S. neqport var. puerto rico, while S. thompson var. berlin 2988 alone could not completely absorb the second phase $\mathrm{H}$ serum of the organism in question. From the above mentioned, $\mathrm{H}$ antigenic formula of this organism is considered to be $b: 1,(3), 5$.

\section{Pathogenicity for mice:}

Five mice fed with the organism all remained normal three weeks after feeding. Intraperitoneal inoculation of $0.01 \mathrm{mg}$ and over (about $10,000,000$ of organisms) of the organism suspended in saline killed mice but $0.001 \mathrm{mg}$ (about $1,000,000)$ failed.

Table 1. Agglutinin titers of the patients' serum against the organism in question

\begin{tabular}{|c|r|r|r|r|}
\hline Serum & $\begin{array}{c}\text { date of } \\
\text { taking blood }\end{array}$ & 1785 & 1786 & 1787 \\
\hline & 4 & 80 & 80 & 40 \\
Patient No. 1 & 9 & 640 & 640 & 640 \\
& 14 & 1,280 & 640 & 640 \\
& 20 & 5,120 & 1,280 & 2,560 \\
& 26 & 5,120 & 1,280 & 1,280 \\
\hline & 4 & 0 & 0 & 0 \\
Patient No. 2 & 14 & 160 & 160 & 160 \\
& 20 & 2,50 & 640 & 640 \\
& 26 & 1,280 & 1,560 & 1,280 \\
& 5 & 0 & 1,280 & 1,280 \\
\hline Patient No. 3 & 9 & 80 & 0 & 0 \\
& 14 & 640 & 640 & 40 \\
& 20 & 1,280 & 1,280 & 640 \\
& 26 & 320 & 640 & 1,280 \\
\hline
\end{tabular}

\section{Agglutinin Titers in the Serum of the Patients}

Table 1 shows the agglutinin titers of the serums of the patients taken on 5 different occasions during the course of the disease for the isolated culturs. As seen in the table, the agglutinin titer of the serum rose in the second sera (9 days after onset) and thereafter. The highest titer was observed in the blood taken on the fourth time (20 days after onset). Some of the blood taken on the fifth time already suggested the fall of the titer.

The agglutinin titers of the serum (20 days after onset) of the patient No. 1 were 1:2,560 for $S$. thompson var. berlin 2988 and $S$. newport 563; 1:5,120 for $S$. newport var. puerto-rico; and 1:320 for $S$. paratyphi $B 8006$ and $S$. anatum 293. S. thompson var. berlin 2988, S. newport 563 and S. newport var. puerto-rico absorbed a part of the agglutinins from this serum, but $S$. 
paratyphi $B$ 8006, S. anatum 293 scarcely absorbed while the organisms (1785, 1786, and 1787) absorbed all the agglutinins from it.

\section{DisCUSSION}

The organism in question is considered to be the causative agent of the acute gastroenteritis described above on the basis of the following reasons:

1) It was isolated from all three patients in that outbreak of acute gastroenteritis.

2) The agglutinin titer rose during the course of the disease.

The antigenic formula of this organism was found to be as VI, VIII:b:1, (3), 5 which indicates that the organism isolated is a new Salmonella type. The authours propose to call it as $S$. nagoya because it was isolated in Nagoya City, Aichi Prefecture, Japan.

\section{SUMMARY}

A description is given to a new Salmonella type, isolated from acute gastroenteritis outbreak: S. nagoya VI, VIII:b:1, (3), 5 .

Thanks are due to Dr. K. Ochiai, the director of the Joto Hospital for his helpful advice and guidance. 